\title{
O (NÃO) LUGAR DA FONÉTICA E DA FONOLOGIA EM LIVROS DIDÁTICOS BRASILEIROS DO ENSINO FUNDAMENTAL ANOS FINAIS
}

\author{
THE (NOT) PLACE OF PHONETICS AND PHONOLOGY IN \\ BRAZILIAN TEXTBOOKS OF ELEMENTARY \\ SCHOOL FINAL YEARS
}

\author{
SIANE GOIS CAVALCANTI RODRIGUES ${ }^{1}$ \\ CRISTINA SÁ2
}

\begin{abstract}
RESUMO: Levando em conta: 1) a importância da Fonética e da Fonologia à reflexão sobre a língua e à ampliação dos saberes linguísticos dos alunos da Educação Básica; 2) o lugar de destaque dos livros didáticos nas salas de aula e 3) o fato de, tradicionalmente, essas áreas fazerem-se presentes de maneira incipiente no currículo escolar, o objetivo desta pesquisa foi analisar o espaço ocupado por esses campos em livros didáticos brasileiros. A investigação, que está acorada em Cagliari (2009), Camara Jr. (2011), Faraco (2012), entre outros, evidenciou que, nas obras analisadas, os conteúdos das áreas em estudo são tratados de maneira superficial e restritiva; a variação, que se limita ao social, ao regional e ao nível do léxico, é abordada como um mero conteúdo da disciplina de Língua Portuguesa e não transversaliza os níveis de análise linguística; faltam conteúdos imprescindíveis não apenas à plena compreensão de certos temas que os próprios livros trazem à tona, mas ao conhecimento, por parte dos alunos, do funcionamento da fonética e da fonologia de sua própria língua materna, o que propicia prejuízos de diferentes ordens à sua formação linguística.
\end{abstract}

Palavras-chave: Fonética. Fonologia. Livros Didáticos.

ABSTRACT: Taking into account the importance of Phonetics and Phonology in reflecting on language and broadening linguistic knowledge of the student's basic education; the highlight of didactic books in classrooms and the fact that, traditionally, these areas have been poorly represented in Portuguese curricula, this work focuses on analyzing how much Phonetics and Phonology are covered by Brazilian didactic books. This study was based on the works of Cagliari (2009), Camara Jr. (2011), Faraco (2012), among others, and our findings reveal that, in such analyzed books, the contents of Phonetics and Phonology are treated superficially and restrictively; the variation, which is limited to the social, regional and lexical levels, is approached as just a Portuguese Language content and doesn't mainstream the linguistic analysis level; essential contents are missing not just to the full understanding of some subjects brought to life by books, but to the knowledge, by students, of the way the Phonetics and Phonology of their own mother tongue, which brings out different types of damage to their linguistic formation.

Keywords: Phonetics. Phonology. Didatic Books.

\footnotetext{
${ }^{1}$ Universidade Federal de Pernambuco, UFPE, Recife, PE, Brasil. sianegois@yahoo.com.br

${ }^{2}$ Universidade de Aveiro, Aveiro, Portugal. cristina@ua.pt
} 


\section{INTRODUÇÃO}

A Fonética e a Fonologia, dois dos três pilares desta investigação, têm importância inconteste à formação linguística dos estudantes da Educação Básica e à ampliação dos seus saberes. Mesmo assim, o lugar reservado a essas áreas no currículo oficial brasileiro é insatisfatório, como demonstra Rodrigues (2020, no prelo), em pesquisa em que analisa a sua presença na BNCC (BRASIL, 2018) dos Anos Finais do Ensino Fundamental. Já Rodrigues e Nascimento (2016) revelam que elas vêm sendo relegadas a segundo plano na formação inicial de professores de Língua Portuguesa (LP) e, em sua práxis, é comum a insegurança acerca do que, de fato, é o objeto de ensino da disciplina.

No que diz respeito aos livros didáticos (nosso terceiro pilar), sabe-se que, há algumas décadas, ele vem suscitando uma grande diversidade de interesses no campo da pesquisa e, a despeito da variedade de abordagens de tais investigações, há, entre elas, um consenso no que diz respeito à sua massiva presença nas salas de aula da Educação Básica e à centralidade do seu uso nas escolas. É esse lugar que os LD têm nas salas de aula a justificativa para a nossa opção de investigá-los. Nesse complexo contexto, objetivamos descortinar o lugar das áreas em pauta em dois LD de português voltados para o $6^{\circ}$ ano do Ensino Fundamental, momento em que, segundo rezam as orientações curriculares em vigor, são retomados e ampliados os saberes construídos no Ensino Fundamental Anos Iniciais.

\section{FONÉTICA E FONOLOGIA: BREVES CONSIDERAÇÕES}

Até chegar aos estudos contemporâneos, o significado dos termos Fonética e Fonologia passou por variações no decurso do desenvolvimento da Linguística. A palavra Fonologia, nos lembra Câmara Jr. (2008), possuía diferentes sentidos no início do século XX, quando Trubetzkoy e os seus colegas do Círculo Linguístico de Praga passaram a usá-la em contraste com a Fonética. Essa última, nos lembra Benveniste (1995), tem sua raiz na obra que marca a entrada de Saussure, com apenas 21 anos de idade, na ciência: o Mémoire sur le système primitif des voyelles dans les langues indo-européennes, ainda que o linguista genebrino tenha delimitado o termo à investigação do desenvolvimento dos sons, ficando o vocábulo "Fonologia" aplicado à ciência geral dos sons da fala. (Camara Jr., op. cit.)

É consenso entre foneticistas e fonólogos que esses dois campos da Linguística se articulam e se ocupam, respectivamente, da descrição e da interpretação dos sons das línguas. Tais campos vêm avançando consideravelmente desde a sua gênese, o que pode ser verificado com a criação do IPA, com os avanços dos estudos experimentais, com as pesquisas voltadas para a Fonologia do Uso e para a hipótese das multirrepresentacionalidades, como nos lembra Cristófaro Silva (informação verbal) $)^{3}$.

${ }^{3}$ Conferência intitulada "Fonologia: Conquistas e Desafios", proferida por Thaís Cristófaro Silva, no dia 16/07/2020, por ocasião do evento Abralin ao Vivo: Linguistics on Line. Disponível em https://www.youtube.com/watch?v=4V6soidUjOw 
Entretanto, como se verá na seção seguinte, as pesquisas que relacionam as áreas em pauta ao ensino da LP são relativamente escassas, tanto no Brasil como em Portugal. Uma breve pesquisa nos veículos de divulgação científica de ambos os países evidenciará esse fenômeno, que é passível de estudo, porquanto, a nosso ver, traz sérias consequências à abordagem dessas áreas na Educação Básica.

\section{FONÉTICA E FONOLOGIA NO CURRÍCULO OFICIAL E NAS DIRETRIZES DO P NLD}

Rodrigues e Sá (2018) empreenderam uma investigação na qual buscaram descortinar o lugar da Fonética e da Fonologia no currículo oficial brasileiro e português. No caso do Brasil, as autoras analisaram a Base Nacional Comum Curricular (BRASIL 2018) do Ensino Fundamental Anos Iniciais e verificaram que tais áreas são abordadas no decorrer de todo o processo de apropriação da escrita, ainda que o fenônemo da variação, que precisa transversalizar a abordagem de todos os níveis de análise da língua, seja tratado como um mero conteúdo de LP. Por seu turno, no Ensino Fundamental Anos Finais, com já afirmado, as referidas áreas são suprimidas, por oposição ao lugar ocupado pela Morfologia e pela Sintaxe, de acordo com Rodrigues (2020, no prelo). Segundo a autora, esse nãolugar, no currículo, dos campos em estudo tem como pressuposta a equivocada ideia de que eles somente são necessários nos primeiros anos de escolaridade dos alunos, quando eles estão se apropriando da escrita e consolidando essa habilidade.

É importante que se considere que os resultados da supramencionada pesquisa refletem um fenômeno que é histórico. Uma análise que se debruce sobre o texto dos Parâmetros Curriculares Nacionais do Ensino Fundamental Anos Finais chegará a conclusões que se assemelham àquelas de Rodrigues (2020, op. cit.), o que corrobora o que defende Cagliari (2009), para quem os currículos escolares priorizam a Morfologia e a Sintaxe, em detrimento de campos como a Fonética, a Fonologia, a Semântica, a Sociolinguística e a Análise do Discurso.

É considerando que os livros didáticos aprovados pelo Programa Nacional do Livro Didático (PNLD) são produzidos em consonância com o que rezam as orientações curriculares nacionais, que passamos, agora, a abordar os princípios que, segundo o guia mais recente (o de 2017, publicado em 2016), devem orientar a escolha de LD de LP, com foco no eixo "conhecimentos linguísticos", os quais se relacionam com a Fonética e a Fonologia. ${ }^{4}$ A leitura desse material deve anteceder a escolha, por parte dos professores, das obras que utilizarão em suas escolas durante três anos. A expectativa é de que as obras "[...] respondam satisfatoriamente aos desafiios gerados pelas transformações do ensino [...] E que, portanto, desenvolvam um trabalho reflexivo com as práticas de linguagem, articulando adequadamente os principais eixos de ensino.” (Brasil, 2016, p. 11).

${ }^{4}$ Essa delimitação é tão somente metodológica, pois compreendemos que os eixos de ensino devem ser abordados de forma articulada. 
$\mathrm{O}$ documento determina que o trabalho com o eixo "conhecimentos linguísticos" aconteça de forma articulada com os demais eixos de ensino, mas que também assuma "[...] determinada autonomia para o tratamento de alguns fenômenos linguísticos, do uso do dicionário ou da norma ortográfica, por exemplo." (BRASIL, 2016, p. 14). Consideramos importante tal observação, pois é preciso levar em conta que tal articulação nem sempre é possível, especialmente quando se está abordando as normas do sistema de escrita alfabética. De uma maneira ou de outra, a tônica é o ensino que contemple diferentes situações de uso e que se volte para a reflexão sobre a língua em suas modalidades oral e escrita, de maneira a desenvolver e ampliar as competências linguísticas dos alunos. Tal reflexão deve abranger as variedades linguísticas sociais e regionais e contemplar tanto as normas urbanas de prestígio, quanto o Português brasileiro contemporâneo em suas modalidades oral e escrita.

Esse ensino deve "[...] aprofundar o processo de inserção qualificada do estudante na cultura escrita" (BRASIL, 2016, p. 16) e, nesse sentido, é pensado para um perfil determinado de aluno que ingressa nesse nível ${ }^{5}$ : espera-se que, no Ensino Fundamental Anos Iniciais, ele tenha construído de maneira satisfatória os saberes relativos aos processos de letramento e de alfabetização. Espera-se, especialmente, que tenha ampliado o seu conhecimento da língua, dominando práticas mais formais de leitura, de escrita, de produção e de compreensão de textos. As obras que não se alinham a tais pressupostos são reprovadas na avaliação, com base em critérios de exclusão relativos à natureza do material textual, à leitura, à produção de textos escritos, ao trabalho com a oralidade e com os conhecimentos linguísticos. Os conteúdos relativos a este último eixo devem, segundo o guia:

- abordar os diferentes tipos de conhecimentos linguísticos em situações de uso, articulando-os com a leitura, a produção de textos e o exercício da linguagem oral;

- considerar e respeitar as variedades regionais e sociais da língua, promovendo o estudo das normas urbanas de prestígio nesse contexto sociolinguístico;

- estimular a reflexão e propiciar a construção dos conhecimentos abordados. (Brasil, 2016, p. 20 - grifos nossos).

Observe-se o destaque dado à necessidade de as obras prestigiarem, em consonância com a necessária ampliação dos saberes do aluno, o uso da língua em situações reais, levando em conta as variedades regionais e sociais. Considerando os nossos objetivos na presente investigação, apliquemos tais critérios à maneira como deve uma obra trabalhar os ditongos, por exemplo. À explicação de que duas vogais não ficam juntas numa mesma sílaba porque a estrutura silábica da

${ }^{5}$ Não poderíamos deixar de observar que tal perfil é uma idealização, como bem o mostra o péssimo desempenho dos alunos da Educação Básica brasileira em avaliações internacionais, como o PISA. Acrescentem-se a isso os dados de avalições nacionais, como o ENEM e a Provinha Brasil, por exemplo. 
LP não o permite, para contemplar as "situações de uso" de que trata o critério primeiro, constante da citação acima, a obra em questão, deve, idealmente, associar a abordagem do processo fonológico da monotongação, que é recorrente na maior parte dos dialetos do Português brasileiro. Ao fazê-lo, concretizar-seia o respeito às "variedades regionais e sociais da língua", bem como o ato da "reflexão", constantes, respetivamente, do segundo e do terceiro critérios acima referidos. No que diz respeito ao ensino da LP, cabe ao Ensino Fundamental Anos Finais propiciar as condições necessárias para que o aluno, aprofundando os saberes construídos no nível de ensino anterior, insira-se na cultura escrita de maneira qualificada:

- aperfeiçoando sua formação como leitor e produtor de textos escritos;

- desenvolvendo as capacidades de leitura e escrita requeridas por esses novos níveis e tipos de letramento;

- ampliando sua capacidade de reflexão sobre as propriedades e o funcionamento da língua e da linguagem;

- desenvolvendo as capacidades associadas aos usos escolares, formais e/ou públicos da linguagem oral. (Brasil, 2016, p. 17)

Os critérios que orientaram a seleção dos LD referidos no PNLD 2017 estão organizados em eixos de ensino. Levando em conta os objetivos desta pesquisa, as nossas considerações a esse respeito limitaram-se aos critérios que tinham relação com os campos em estudo, os quais se encontram nos eixos relativos à natureza do material textual, ao trabalho com a oralidade e ao trabalho com os conhecimentos linguísticos.

Um dos critérios relativos à natureza do material textual determina que uma obra deve "[...] ser representativa da heterogeneidade própria da cultura e da escrita - inclusive no que diz respeito a autoria, a registros, estilos e variedades (sociais e regionais) linguísticas do Português" (BRASIL, 2016, p. 19). Em se tratando dos campos em estudo nesta investigação, para que uma obra seja representativa da heterogeneidade da cultura, no que tange às variedades linguísticas, ela deve, para citar apenas um exemplo dentre muitos, apresentar ao aluno uma abordagem da variação fonética do Português falado nas diferentes regiões do Brasil, fugindo aos estereótipos comumente encontrados em LD, quando tratam dessa problemática, como ver-se-á na análise. Por fim, no eixo dos conhecimentos linguísticos, encontramos critérios segundo os quais as obras devem

[...] abordar os diferentes tipos de conhecimentos linguísticos em situações de uso, articulandoos com a leitura, a produção de textos e o exercício da linguagem oral" e "considerar e respeitar as variedades regionais e sociais da língua promovendo o estudo das normas urbanas de prestígio nesse contexto sociolinguístico. (BRASIL, 2016, p. 20). 
O primeiro critério demanda uma abordagem complexa por parte dos LD, ao relacionar os conhecimentos linguísticos em situação de uso com os diferentes eixos de ensino. Subjacente a tal critério, está a ideia de que os LD não devem separar a abordagem dos conhecimentos linguísticos das situações de uso da língua de que participamos cotidianamente. Além disso, tal abordagem deve articular-se com os diferentes eixos de ensino. Em se tratando da Fonética e da Fonologia, isso significa que as obras aprovadas devem, por exemplo: no que diz respeito ao eixo da leitura, abordar os aspectos fonológicos e prosódicos específicos da oralidade; no que tange ao eixo da produção de textos, abordar as especificidades do sistema de escrita alfabética em relação com os sons da fala; quanto ao eixo da oralidade, identificar características sociais, regionais, urbanas e rurais relativas à variação fonética. Tal critério está intimamente relacionado com o segundo anteriormente citado, ao passo que à abordagem dos diferentes tipos de conhecimentos linguísticos em situação de uso é imprescindível o respeito à variação linguística.

\section{ANÁLISE DOS DADOS}

As obras escolhidas para esta pesquisa deveriam: i) ser voltadas para o $6^{\circ}$ ano do Ensino Fundamental Anos Finais; ii) ter sido aprovadas no último Programa Nacional de Livros Didáticos (Brasil, 2016); iii) ter sido publicadas por editoras que possuíssem ampla distribuição nas escolas brasileiras. Assim, o corpus foi composto pelos LD seguintes: Para viver juntos: Português, $6^{\circ}$ ano, de autoria de Cibele Lopresti Costa, Greta Marchetti e Jairo J. Batista Soares - designado por Livro Didático 1 (LD1) - e Singular e plural: leitura, produção e estudos de linguagem, $6^{\circ}$ ano, de Laura de Figueiredo, Marisa Balthasar e Shirley Goulart - designado por Livro Didático 2 (LD2). Na primeira parte da análise de cada LD, fizemos uma sucinta descrição da estrutura da obra, para, então, efetuar o levantamento dos dados e a respectiva análise, em conformidade com os objetivos propostos.

\section{A) Livro Didático 1}

O LD1 é composto por nove capítulos, cada um dos quais é estruturado em torno de um gênero textual central e de outros gêneros secundários. Logo após um curto texto de apresentação da obra, há uma secção intitulada Conheça o seu livro, onde o leitor pode ter um acesso prévio à estrutura da obra e aos objetivos de cada uma de suas partes. Os conteúdos das áreas em investigação são abordados no LD1 nos Capítulos 1, 2, 6 e 8

No Capítulo 1, é na secção Questões de escrita (entre as páginas 41 e 43) que conteúdos da fonética e da fonologia são abordados pela primeira vez no LD1. Do ponto de vista didático-pedagógico, a sequência a partir da qual tais saberes aparecem no texto favorece a abordagem dos conteúdos subsequentes. Apresenta-se a definição de letra e de fonema, por meio da seguinte estratégia: há 
três imagens de animais (um pato, um rato e um gato), seguidas de um comentário segundo o qual os nomes daqueles animais são bastante parecidos, diferenciandose apenas quanto ao primeiro som. Oberva-se aí uma preocupação dos autores em didatizar o conceito de par mínimo. Adiante, há uma atividade de oito questões que versam sobre pares mínimos (ainda que o termo não seja referido) e sobre a relação grafema/fonema, ainda que isso seja feito de maneira muito superficial, porquanto não são verificadas considerações de grande relevo acerca do fato de, em Português, a questão da memória etimológica relativizar a referida relação. Nesse interim, são apresentadas as definições de fonema e de letra. A seguir, há um quadro onde se observam as vinte e seis letras do alfabeto da língua portuguesa, mas não há, por outro lado, qualquer representação dos fonemas do Português brasileiro. Essa ausência, como explicitado adiante, prejudica o desenvolvimento de habilidades importantes relativas, por exemplo, à reflexão acerca do caráter abstrato da relação grafema/fonema, que é de suma importância à construção dos saberes relativos aos princípios da escrita alfabética.

No Capítulo 2 (da página 78 à 81), na seção Questões de Escrita, são explicitadas as características dos encontros consonantais e dos dígrafos e há uma atividade acerca do assunto, que é composta por três questões. Mais uma vez, a ausência, na obra, da representação dos fonemas do Português brasileiro potencializa a abstração da relação grafema/fonema e não contribui com a compreensão dos conceitos de dígrafo e de encontro consonantal apresentados na própria obra. No mesmo capítulo, na subsecção Atividades globais/Reflexão linguística (p. 80), encontra-se um exercício de duas questões. A primeira tem quatro perguntas (transcritas abaixo), que são estruturadas em torno da letra da música As mina de Sampa, de autoria de Rita Lee, e abordam a varição linguística diastrática:

a) Na letra da música, Rita Lee faz uma brincadeira com o modo de falar que caracteriza um grupo de pessoas de uma região do Brasil. De onde é esse grupo?

b) Identifique na letra da música exemplos de expressões utilizadas pelos jovens.

c) Para registrar as palavras mortadela, berinjela e apartamento, o texto utiliza as grafias mortandeila, berinjeila e apartameintu. Por que essas palavras foram registradas dessa maneira?

d) A palavra mina refere-se a uma mulher jovem. Você conhece outras gírias com o mesmo significado?

Quadro 1. Primeira atividade sobre variação linguística do LD1

(Fonte: Costa et al., 2015, p. 80)

A questão a) introduz o tema da variação diastrática (ainda que não mencione o termo), por meio do questionamento acerca do "modo de falar" de determinado grupo social que reside no sudeste brasileiro. A questão b), por seu turno, dando continuidade ao tema da anterior, situa a problemática na variação lexical, assim 
como o faz a última questão. Foi na questão c) que a obra fez um movimento para tratar dos processos fonológicos, já que a pronúncia de mortadela, berinjela e apartamento como mortandeila, berinjeila e apartameintu são representativas de epêntese e de alçamento. Entretanto, o que poderia render uma profícua maneira de tratar o assunto é, na realidade, uma pergunta que se limita a abordar de forma superficial a relação fala e escrita. Tal superficialidade beira os conhecimentos do senso comum acerca do "modo de falar" desse grupo social e, como não associa a variação linguística à fonética e à fonologia, não favorece o desenvolvimento de competências importantes relativas ao respeito e à valorização das diferentes normas.

A segunda questão, por sua vez, trata da variação diacrônica (especificamente no que diz respeito à mudança da grafia das palavras), usando como estratégia a análise de um texto publicitário do início do século passado e, para isso, não recorre a conceitos das áreas em estudo, reiterando a opção da questão anterior em dissociar a variação dos níveis de análise linguística.

Ainda no Capítulo 2, na secção Reflexão linguística (p. 60), a obra apresenta as definições de variedade linguística e regional, de varição linguística e de normas urbanas. Para isso, inicia a reflexão por meio da exploração da variação lexical constante de um pequeno excerto de um conto popular. Na página seguinte, na secção Reflexão linguística na prática, há uma atividade de duas questões, a segunda das quais dá continuidade à abordagem da varição lexical, especialmente, a que se observa entre o Português brasileiro e o Português lusitano e usa como estratégia uma proposta de leitura de uma notícia extraída de um jornal de Portugal. Por sua vez, a primeira questão é estruturada em torno de um trecho da música Vaca Estrela e Boi Fubá, de autoria do cantor e compositor Patativa do Assaré, e possui seis alternativas, como se pode ver no quadro abaixo:

a) $\mathrm{Na}$ primeira estrofe da canção, é revelada uma transformação na vida do boiadeiro. Que transformação é essa? Quais versos comprovam sua resposta?

b) Qual termo dessa estrofe está em desacordo com a norma-padrão? Como essa palavra é registrada na norma padrão?

c) Qual o efeito de sentido produzido ao usar esse termo dessa maneira?

d) Procure no dicinário o significado das palavras medonha, tangeu e aboaiar no texto.

e) $\mathrm{Na}$ letra, o eu lírico retrata um espaço. Que espaço é esse?

f) É possível estabelecer uma relação entre o uso das palavras indicadas no item de o espaço retratado na canção? Justifique.

Quadro 2. Segunda atividade sobre variação linguística do LD1

(Fonte: Costa et al., 2015, p. 61)

A estrofe a que se refere a maior parte das alterntivas constantes do Quadro 18 é a seguinte: 


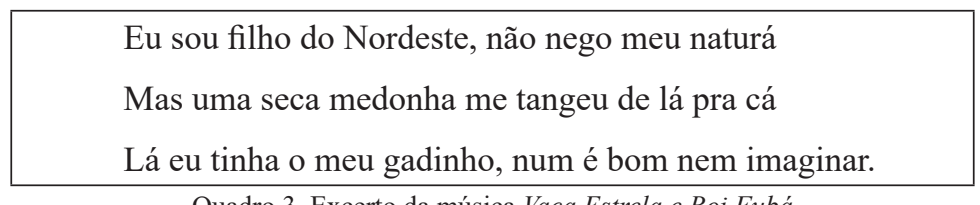

Quadro 3. Excerto da música Vaca Estrela e Boi Fubá

(Fonte: Costa et al., 2015, p. 61)

Na alternativa b), o aluno é chamado a idenficar o termo constante da estrofe que está em desacordo com a norma padrão e a reescrevê-lo em conformidade com essa norma. A leitura do excerto mostra, entretanto, que, em vez de um, há dois termos que se distanciam do padrão, quais sejam: naturá e num, ambos exemplos de processos fonológicos. Em naturá (em vez de natural), temos o apagamento de um fonema no fim do vocábulo. Em num (em vez de não), verificam-se três processos: apagamento de segmento medial (a), alçamento da vogal final (o $o$ da palavra não passa a ser $u$ ) e a nasalização. Ou seja, ainda que o segmento apresentado pela obra seja muito rico para a abordagem do referido assunto, os autores optam por comparar tal fenômeno com o que prescreve a norma padrão e solicitar que o aluno o corrija, o que, a nosso ver, representa uma abordagem didático-pedagógica meramente transmissiva, que em nada contribui para o combate ao preconceito linguístico e para a superação da ideia segundo a qual o que foge ao padrão é errado e precisa ser corrigido.

No Capítulo 6, na seção Questões de escrita (pp. 216 e 217), o conteúdo tratado é hiatos e ditongos. O aluno é orientado a observar um grupo de nove palavras em que há vogais juntas e a separá-las em dois grupos: um grupo em que elas são pronunciadas na mesma sílaba e outro em que não o são. A seguir, apresentam-se as seguintes definições:

Quando as vogais vizinhas estão na mesma sílaba, uma delas (a de som mais fraco) passa a ser chamada de semivogal. O som da vogal e da semivogal juntas na mesma sílaba chama-se ditongo. Exemplo: i-gual (i-gual). Quando as vogais vizinhas são pronunciadas em sílabas diferentes, ocorre hiato. Exemplo: saúde (sa-ú-de). [...] Quando a segunda vogal do hiato for i ou u tônicos, acompanhados de ou não de s, ela será acentuada. [..] Há exceção a essa regra. Não são acentuados os hiatos terminados em i seguidos de nh. Não são acentuados os hiatos em que o i ou o u finais formam sílaba com outra letra que não o s.

Quadro 4. Definições de semivogal, ditongo e hiato apresentadas no LD1

(Fonte: Costa et al, 2015, p. 216 - Grifos das autoras)

Conforme referido anteriormente, não há um consenso entre os linguistas acerca da existência de ditongos no Português. Por exemplo, Mattoso Câmara Júnior (2011) considera que eles não constituem um traço fonêmico geral do Português. Essa falta de consenso é motivada pela grande variação linguística observável no Português falado em Portugal e em suas ex-colônias. Nessa abordagem, fica inviabilizado o desenvolvimento de habilidades que dependem 
dos conhecimentos prévios, já que eles não foram abordados pelo livro. Para ilustar tal afirmação, observe-se que não é possível ao aluno compreender tudo o que envolve a realização dos ditongos sem que, antes, o professor tenha abordado a caracterização das vogais e dos glides do ponto de vista fonético, a articulação dos ditongos, a variação linguística que caracteriza a produção de segmentos que ora são ditongos, ora são hiatos, os ditongos crescentes e decrescentes, a redução de ditongos etc. Nesse sentido, as definições de semivogal, ditongo e hiato apresentadas pelo LD1 são muito sucintas, superficiais e restritas ao que reza a norma padrão, porquanto não há qualquer menção à variação linguística, fenômeno indispensável para que se compreenda o assunto em pauta.

O emprego do $g$ e do $j$ é discutido no Capítulo 8, na seção Questões de escrita, último segmento da obra em que conteúdos da fonética e da fonologia são abordados. É apresentado um trava-línguas em que as referidas consoantes são articuladas repetidas vezes e, a seguir, o aluno é chamado a responder às perguntas seguintes:

a) Observe as consoantes das palavras que compõem esse trava-línguas. Qual é o som que mais se repete?

b) Quais são as letras que representam esse som?

Quadro 5. Atividade sobre o emprego do $g$ e do $j$ do LD1

(Fonte: Costa et al., 2015, p. 282)

As perguntas são estruturadas em torno da relação grafema/fonema que rege o princípio geral da escrita alfabética. Assim, o aluno precisa, depois de identificar o som que mais é repetido no trava-línguas, indicar as letras que lhe são correspondentes. Ao fazê-lo, chegará à conclusão de que, na LP, a relação grafema/ fonema não é um a um, porquanto um mesmo fonema pode ser presentado por mais de uma letra (e vice-versa).

A obra em análise é voltada para o professor e, sendo assim, as respostas aos exercícios ficam disponíveis nas margens laterais de cada página. Ainda que fuja aos objetivos desta pesquisa investigar tais respostas, abrimos, aqui, uma exceção, pois as respostas a estas duas questões são importantes à construção do nosso argumento:

Resposta à letra a): $\mathrm{O}$ som $/ 3 /$. Professor, os alunos podem responder oralmente a essa questão ou indicar o som mais repetido com o exemplo de uma palavra em que ele aparece. Por exemplo: o som inicial da palavra girafa.

Resposta à letra b) $\mathbf{g}$ e $\mathbf{j}$

Quadro 6. Respostas previstas pelo LD1 para a primeira questão da atividade constante da página 282 (Fonte: Costa, et al, 2015)

Na resposta à primeira questão, depois de informar qual é o som, a obra sugere ao professor a opção de levar os alunos a responderem oralmente, indicando qual é o som e apresentando palavras do trava-línguas em que ele figura. Ao fazer essa 
proposta, o LD1 procura dar ao professor uma solução para uma grande lacuna da obra, que é a inexistência da abordagem do quadro fonêmico (bem como do fonético) do Português, o que é de fundamental importância para que os estudantes entendam por que se diz que a LP possui uma representação gráfica alfabética com memória etimológica. Em outras palavras, o LD1 reconhece uma lacuna, mas, infelizmente, a opção para preenchê-la ratifica o que verificamos, na pesquisa de que trata a nota de rodapé de número 2, aquando da análise da BNCC Anos Finais do Ensino Fundamental (Brasil, 2016): a fonética e a fonologia permanecem, deliberadamente, à margem dos objetos de ensino do Português, fenômeno que, não resta dúvidas, precisa ser sistematicamente investigado e discutido. Quando, por ventura, tais áreas são contempladas, a abordagem didático-pedagógica observada, longe de ser voltada ao desenvolvimento de competências e habilidades, é de natureza transmissivista, conteudista.

\section{B) Livro Didático 2}

O LD2 é composto por três grandes secções, cada uma das quais dá prioridade ao eixo de ensino que o intitula. O Caderno de leitura e produção divide-se em três unidades, onde são abordados diversos gêneros textuais, como diário íntimo e ficcional, esquete, causos de assombração, debate, apresentação oral, crônica, lenda e mito. No Caderno de práticas de literatura, há duas unidades: a primeira aborda questões relativas ao papel e ao funcionamento de bibliotecas escolares e a segunda apresenta reflexões sobre o que é a literatura, trabalhando gêneros literários e suas características. Por fim, o Caderno de estudos de língua e de linguagem, é composto por três unidades que abordam respectivamente os tópicos: língua, linguagem e variação; língua e gramática normativa; ortografia e pontuação.

Os conteúdos das áreas em investigação neste estudo raramente fazem-se presentes na obra. Quando aparecem, a abordagem é indireta e superficial: ao tratar da variação linguística, a obra restringe-se ao social e, por vezes, reitera a estereotipação do fenômeno, ao relacioná-lo a textos de humor. É no Caderno de estudos de língua e de linguagem que os temas da variação linguística e da relação fala/escrita aparecem pela primeira vez na obra. A Unidade 1, do Caderno de estudos de língua e linguagem, denominada Língua e linguagem, tem início com a apresentação de duas imagens que retratam apresentações de grupos de dança (páginas 188 e 189). A seguir, surgem perguntas acerca do que é língua, linguagem e gramática. Logo depois, com os mesmos objetivos e usando estratégias semelhantes, a obra explora outras duas imagens (uma fotografia da escultura "Narcísio a partir de Caravaggio", de Vik Muniz, e outra, que reproduz a pintura "Narciso", desse pintor italiano). Adiante, por meio de um exercício que propõe a análise de duas tiras, há a reflexão acerca do papel da linguagem, do aspecto interativo da língua, das noções de interlocutor, locutor e locutário. Paralelamente, com o objetivo de aprofundar as concepções constantes da introdução do Caderno, são apresentados outros gêneros textuais (textos publicitários, textos da literatura oral popular, letra de canção, poema, conto, crônica, piada) acompanhados por 
exercícios que abordam temas como linguagem verbal e não verbal, enunciado, discurso e intencionalidade discursiva.

A Unidade 2 - Língua como um conjunto de variedades - aborda a variação histórica por meio da exploração de textos escritos em Português de diferentes épocas, mas não trata da evolução fonética das palavras - por exemplo, em sua passagem do Latim para o Português - de maneira que a abordagem da variação restringe-se ao social e ao regional e contempla apenas questões lexicais. Para ilustrar essa questão, tomemos como exemplo uma tira de Moisés Gonçalves (página 213), que mostra um diálogo entre o personagem Mutum, que mora na cidade, e sua tia, que reside na zona rural.

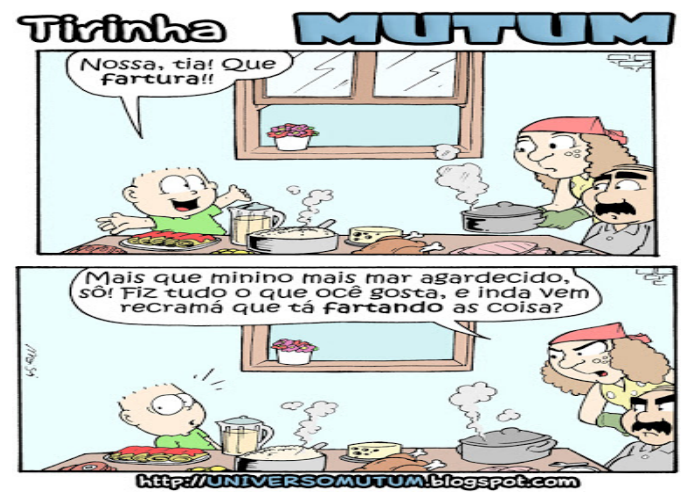

Figura 1. Tirinha sobre variação linguística, constante da página 213

(Fonte: Costa, et al, 2015)

O humor da tira gira em torno das palavras fartura e fartando, que o autor destacou. $\mathrm{O}$ processo fonológico do rotacismo presente nesses vocábulos (como em mar e recramá) é muito frequente na fala de brasileiros pertencentes às camadas sociais mais desfavorecidas, de baixo ou nenhum nível de escolaridade. De igual maneira, agardecido, ocê e inda, que exemplificam os processos de transposição e de aférese, são de uso comum nesses grupos sociais. Ou seja, apesar de o texto oferecer uma rica oportunidade para a reflexão acerca do preconceito linguístico, da variação linguística e da construção de estereótipos, a obra não adentra em conteúdos da fonética e da fonologia que seriam imprescindíveis a tão importante discussão e, do ponto de vista didático, não favorece o necessário diálogo entre os eixos dos Conhecimentos Linguísticos e Gramaticais e da Leitura. Além disso, trata a variação como um conteúdo e não como um fenômeno que transversaliza os níveis de análise linguística e limita-a, como já referido, ao social e ao regional. Passemos à analise do exercício que explora a tira em pauta, o qual reproduzimos no quadro abaixo: 
1. Explique o que acontece nas duas cenas.

2. O que você pode dizer sobre o modo como a tia de Mutum fala, considerando como está representada na escrita?

3. Observe o significado da palavra fartura, usada por Mutum.

FARTURA s.f. (sXIV) 1 estado de farto $\mathbf{2}$ quantidade mais do que suficiente; abundância 2.1 abundência de comestíveis ou provisões. INSTITUTO ANTÔNIO HOUAISS. Dicionário eletrônico Houaiss da língua portuguesa. Rio de Janeiro: Objetiva, 2010 (Fragmento)

a) Podemos dizer que a graça da tira se apoia no uso desta palavra. O que o menino quis dizer ao usar tal palavra?

b) Como a tia entendeu o que ele disse?

c) Levando em consideração o que você observou sobre a fala da tia, que causou o mal-entendido?

4. A expressão do garoto, no segundo quadrinho, indica certa surpresa. Por quê?

5. Se o menino quisesse dar à sua fala o sentido que a tia deu, ele teria feito uso de uma palavra semelhante à que usou. O que ele diria?

6. Observe três palavras retiradas da fala da tia: mar, recramá, fartando. Veja, agora, essas mesmas palavras faladas e escritas de outra maneira: mal, reclamar, faltando.

a) As últimas palavras apresentadas poderiam substituir as faladas pela tia e dariam sentido ao texto?

b) O que os dois grupos de palavras têm de diferente?

7. Você diria que Mutum e seus tios compartilham a mesma maneira de fala a língua portuguesa? Explique.

Quadro 7. Exercício sobre variação linguística do LD2

(Fonte: Figueiredo et al., 2015, p. 214)

A análise da atividade acima mostra que a obra se exime de tratar a variação do ponto de vista da fonologia, ainda que o processo de construção de sentidos da tira tenha como base processos fonológicos importantes a uma abordagem didático-pedagógica que possibililite uma reflexão mais profunda acerca desses fenômenos. Não estamos, com isto, dizendo que a perspectiva didáticopedagógica que se observa é de cunho transmissivo, tanto é que se observa, por exemplo, que o exercício propõe-se à discussão acerca da construção de sentidos das palavras em destaque na tira, bem como do papel dos interlocutores nessa construção. Chamamos, entretanto, a atenção para o fato de que esse não-lugar das áreas em estudo na obra em análise tolhe o direito dos alunos de ter acesso a saberes muito importantes acerca de sua própria LM. O livro não oferece, por exemplo, subsídios teóricos suficientes para que o aluno dê uma resposta que não 
seja oriunda do senso comum à letra b) da sexta questão. Para dar conta dessa lacuna, o LD2 utiliza mecanismos para evitar abordar a fonética e a fonologia. Isso é especialmente evidente no excerto abaixo, que, apesar de ter como título Troca de letras e sons nas palavras, não faz qualquer menção à fonologia, recorrendo a expressões genéricas oriundas do senso comum, como "jeito de falar".

\section{Troca de letras e sons nas palavras}

Dependendo do grupo social a que pertencemos e da nossa formação escolar, os nossos falares podem serdiferentes. Costumamos falar como falam as pessoas que nos cercam proque aprendemos a falar com elase, no dia a dia, também nos comunicamos com elas. Se desde pequenos frequentamos a escola, lemosmuitos livros, o jeito de falarmos poderá ser diferente do jeito de falar de pessoas que nunca foram à escolae não convivem com livros.

Quadro 8. Considerações do LD2 acerca das variedades da língua

(Fonte: Figueiredo et al., 2015, p. 214)

Voltando à discussão acerca da tira em pauta, consideramos que as piadas que versam sobre a variação linguística constituem uma das expressões de preconceito linguístico mais arraigadas e dissimuladas socialmente e que possuem maior poder depreciativo, porque colocam certos grupos sociais na desconfortável posição de quem é motivo de troça, de riso. Isso é especialmente marcante no Brasil, país cujas desigualdades sociais são abissais, onde as normas linguísticas praticadas pelos grupos mais desfavorecidos são as que são mote da tal zombaria. Ao usar um texto de humor para abordar a questão sem que faça uma reflexão dessa natureza, o LD2, contraditoriamente, reitera a ideologia do preconceito, a qual tenta combater em passagens como a que reproduzimos no quadro abaixo.

\section{Variedades e preconceito linguístico}

Dentre as variedades da língua, há as variedades urbanas de prestígio, faladas pelas classes sociais que vivem nas grandes cidades e que têm maior poder econômico e grau de escolaridade. [...] Em muitas situações de comunicação, as pessoas com quem interagimos [...] esperam que usemos essas variedades porque, historicamente, a sociedade sempre as valorizou. É por isso que convivemos com a noção de "erro": se não sigo as normas dessas variedades urbanas de prestígio, falo errado!

O preconceito linguístico nasce daí: da ideia de que quem não fala ou não domina essas variedades de prestígio é inferior. Como você verá, esse modo de ver é que constitui um erro! Um erro de compreensão do que é a língua.

Quadro 9. Considerações do LD2 acerca das noções de variedades da língua e de preconceito linguístico (Fonte: Figueiredo et al., 2015, p. 214 - grifos das autoras)

A opção supracitada de evitar abordar conceitos da fonética e da fonologia também pode ser exemplificada por uma questão constante de um exercício 
que explora o poema $\mathrm{Ai}$ ! Se sesse, do poeta popular Zé da Luz (página 215). O texto apresenta vários exemplos de processos fonológicos, a maioria dos quais é completamente ignorada pelo LD2, que se limita a abordar de maneira superficial apenas um, como se pode ver no quadro abaixo:

Identifique no texto as palavras que você consegue perceber que estão escritas de forma diferente daquela que você costuma encontrar em textos de livros, jornais e revistas.

a) Como você costuma encontrar essas palavras escritas em jornais e revistas?

b) Em uma dessas palavras também há a troca do $\mathbf{I}$ pelo $\mathbf{r}$. Localize-a.

Quadro 10. Primeiro exerc. sobre variação linguíst. do LD2

(Fonte: Figueiredo et al., 2015, p. 215)

Observe-se que a ação de localizar as palavras em que há troca de letras, do ponto de vista didático-pedagógico, não favorece uma ação reflexiva acerca do fenômeno do rotacismo, tão cara ao combate ao preconceito liguístico. Por seu turno, a opção por recorrer a tiras de humor para abordar a variação linguística, de modo a reiterar estereótipos sociais e, consequentemente, fugir à discussão acerca de fenômenos fonológicos de relevo à formação linguística dos alunos, também se verificou em um exercício elaborado a partir de uma tira de autoria de Cedaz (página 222), copiada abaixo:

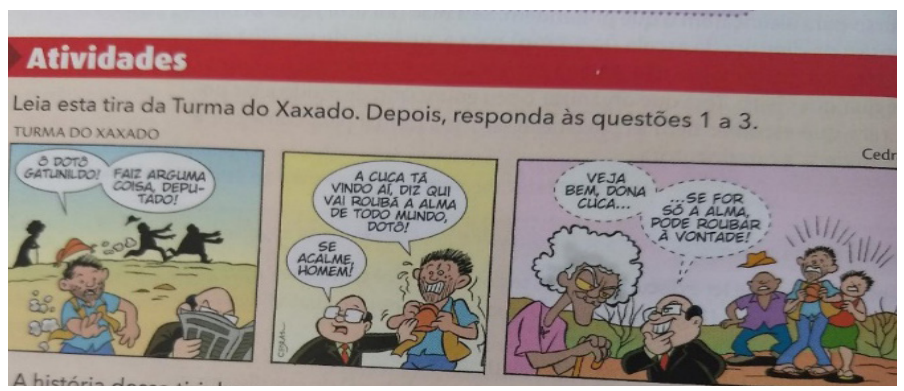

Figura 2. Tirinha sobre variação linguística, constante da página 222

(Fonte: Costa, et al, 2015)

Observe-se que a imagem campestre e as roupas simples das personagens que fogem da suposta bruxa indicam que a história tem como cenário a zona rural. Por sua vez, as vestes do senhor, a maneira respeitosa com que o sujeito se reporta a ele ("dotô Gatunildo", "deputado") e o fato de ele estar lendo um jornal dão a entender que se trata de uma pessoa culta. Nas entrelinhas dessa cena, está a equivocada ideia de que os grupos sociais de uma dada localidade são homogêneos, de maneira que todos os que são da cidade e vestem-se formalmente falam a mesma variante - a de prestígio - e todos os moradores das zonas rurais usam, por oposição, uma variante desprestigiada. O exercício que explora a tira é apresentado no quadro abaixo: 


\section{A história dessa tirinha se passa no campo ou na cidade? Por quê?}

Note que Gatunildo não fala a língua portuguesa da mesma maneira que o outro homem (o de chapéu e colete). Um exemplo disso é a palavra roubar, que aparece de modo diferente na fala de cada um.

a) Se o autor da tira quisesse indicar que Gatunildo fala português da mesma maneira que o outro homem, como seria a fala dele?

b) O que a diferença na maneir de falar pode indicar sobre a condição social dessas duas personagens?

c) As roupas que as duas personagens usam confirma ou contradiz essa diferença na condição social? Explique.

Quadro 11. Segundo exerc. sobre variação ling. do LD2

(Fonte: Figueiredo et al., 2015, p. 222)

A exploração da tira através desse exercício segue os mesmos moldes daquele que analisamos anteriomente: limita a variação linguística ao regional e ao social; trata-a de maneira estereotipada, porque a associa a textos de humor e evita abordar os processos fonológicos que caracterizam, no texto em análise, as falas das personagens que moram no campo. Além disso, perde-se uma cara oportunidade de propiciar um diálogo entre diferentes eixos, como o dos Conhecimentos Linguísticos e o da Leitura.

A Unidade 2 do Caderno de estudos de língua e linguagem, denominada Lingua e gramática normativa, tem início com apresentação de uma fotografia da exposição Menas: o certo do errado, o errado do certo, realizada no Museu da Língua Portuguesa, em junho de 2010 (página 224). A seguir, há um exercício que reflete acerca do que é língua e do que é erro. Para tanto, a obra contrapõe a referida imagem a um texto verbal sobre o assunto. O objetivo da unidade é, nas palavras das autoras, "[...] refletir mais sobre a nossa língua, por meio da observação e análise de aspectos da gramática normativa e de seus usos." (FIGUEIREDO et al., 2015, p. 225 - grifo das autoras). No decorrer da unidade, gêneros textuais diversos (poema, conto, tira, história em quadrinho, crônica, reportagem, letra de canção, notícia, trava-língua, resenha crítica de filme) são explorados na abordagem dos seguintes conteúdos: gramaticalidade, gramática, frase e oração, classes de palavras, ortografia, pontuação e acentuação.

A secção sobre ortografia é introduzida com um exercício em que o aluno é chamado a selecionar, em um dado texto, palavras em que se observa o rr e aquelas em que a letra $\mathbf{r}$ se faz presente em diferentes posições. Depois da seleção, o estudante deve distribuir tais palavras em cinco grupos em que o $\mathbf{r}$ é usado em início de palavra, em posição intervocálica, seguido de consoante na mesma sílaba e em posição de coda silábica. Além disso, há o grupo onde ele deve inserir palavras com rr. A seguir, o estudante deve comparar os diferentes grupos para identificar em que elas se assemelham e se diferenciam, na segunda questão, que transcrevemos abaixo: 
2. Compare as palavras dos grupos A e B e analise o que elas têm em comum e que têm de diferente em relação ao som e à grafia do $r$.

Quadro 12. Exercício sobre ortografia do LD2

(Fonte: Figueiredo et al., 2015, p. 222)

Mais uma vez, o LD2 evita abordar conceitos da fonética e da fonologia que são caros à reflexão sobre o sistema e escrita alfabética: as autoras solicitam que os alunos comparem os sons das palavras envolvidas na questão, mas se eximem de abordar os fones e os fonemas da língua portuguesa. Na parte lateral da mesma página, há o seguinte texto:

Para escrever as palavras, usamos as letras do alfabeto, que tem um total de 26 letras. Essas letras - que representam os sons que usamos ao falar as palavras - podem ser divididas em dois grandes grupos: as vogais (e semivogais) e as consoantes. As letras que representam as vogais (e semivogais) são a, e, i, o, u, $\mathbf{y}($ com som de $/ \mathbf{i} /)$, w (com som de /u/). E as que representam as consoantes são b, c, d, f, g, h, k, l, m, p, q, r, s t, v, x, w (com som de /v/), $\mathbf{z}$.

Quadro 13. Apresentação das letras do alfabeto no LD2

(Fonte: Figueiredo et al., 2015, p. 267)

Como se pode observar no excerto acima, apesar de abordar a relação grafema/fonema, o LD2 limita-se a apresentar as letras e abstem-se de fazer qualquer referência aos seus respectivos fonemas, tampouco de tratar dos fones, porque, mais uma vez, a variação linguística sequer é mencionada no texto. No segmento em análise, o LD2 aborda as diferentes posições que o r ortográfico ocupa nas palavras. Como se sabe, no que diz respeito à realização sonora, esse segmento consonantal apresenta grande variação, a depender do contexto em que se faz presente e da região dialetal a que pertence o falante. Tome-se, como exemplo, no Português brasileiro, a diversidade de pronúncias do $r$ ortográfico quando em contexto de coda silábica. A palavra mar ilustra bem a questão. Ela pode ser pronunciada como ['mah], ['maX], ['mar], ['mar], se o falante for, respetivamente, de Recife, do Rio de Janeiro, do Rio Grande do Sul ou de certas cidades do interior de São Paulo.

Esse dado mostra que o livro, apesar de conseguir explorar didaticamente a ortografia, apresenta uma grave lacuna no que diz respeito à abordagem da relação entre as letras e os sons que elas representam, o que não favorece o desenvolvimento da habilidade de olhar de maneira investigativa para a sua própria língua. Não estamos, com isso, dizendo que, no que diz respeito ao ensino da ortografia, as estratégias de memorização a que a obra recorre não sejam necessárias. Elas o são, especialmente quando entra em cena a questão da memória etimológica (que relativiza a relação grafema/fonema). Entretanto, no que diz respeito à questão supracitada, há que haver uma reflexão detida acerca da neutralidade da grafia em relação à fala, da variação da pronúncia e do necessário respeito às diferentes variantes. Isso é particularmente importante em se tratando de variedades 
desprestigiadas socialmente, onde se observa o fenômeno do rotacismo. Por tais razões, consideramos que, nessa seção em específico, a abordagem didáticopedagógica do LD2 possui caráter meramente transmissivo.

O problema acima referido é reiterado no LD2 em toda a abordagem da ortografia, que não contempla as diferentes relações que ocorrem entre as unidades gráficas e as sonoras, como: as relações biunívocas, em que um fonema corresponde a um grafema e vice-versa; a relações cruzadas, em que um fonema corresponde a mais de um grafema e um mesmo grafema representa diferentes fonemas (FARACO, 2012).

Passemos, agora, ao último excerto da obra em análise que se relaciona com os objetivos desta pesquisa. Na parte final da Unidade 2 do Caderno de estudos de língua e linguagem, o conteúdo trabalhado é a acentuação das oxítonas, paroxítonas e proparoxítonas. Para tanto, o LD2 precisa recorrer à noção de sílaba e o faz nos seguintes termos:

Sílaba - Quando falamos uma palavra devagar, podemos perceber que a dividimos em pequenos "pedaços". Experimente falar a palavra abraço bem devagar... Viu só? A cada vez que você movimentou a boca, saíram um ou mais sons: $a$-bra-ço. Cada um desses sons que sai a cada emissão de voz, quando pronunciamos uma palavra, é chamado de sílaba. Para falar a palavra abraço, movimentamos a boca três vezes: na primeira, emitimos só um som (a) na segunda, emitimos três sons sequenciados (bra) e, na terceira, outros dois sons em sequência (ço).

Quadro 14. Definição de sílaba apresentada no LD2

(Fonte: Figueiredo et al., 2015, p. 278)

Os saberes da fonologia são fundamentais à explicação da estrutura da sílaba. Quando fazemos tal afirmação, não estamos, em absoluto, defendendo a formação, no contexto da Educação Básica, de especialistas na área, mas advogando a favor de uma didatização desse campo que não seja redutora ao ponto de eliminar qualquer referência sua dos LD. E é exatamente isso o que os excertos do LD2 analisados até agora revelam. Em outros termos, no que se refere à noção de sílaba, o professor não deve explicar aos alunos o que é coda, ataque e rima, como o bem afirma Roberto (2016), mas deve ensinar, por exemplo, que as diferentes línguas possuem princípios a partir dos quais se organizam as suas sílabas, e que, no caso do Português, a vogal sempre ocupará a posição de núcleo da sílaba e que as sílabas possuem diferentes estruturas. Esses saberes em muito auxiliarão na compreensão de certos aspetos da oralidade e da escrita. A definição redutora de sílaba que transcrevemos mostra que não é isso a que se propõe a obra em pauta. Na sequência, o LD2 aborda os conceitos de hiato e de ditongo, que foram trancritos no quadro abaixo. 


\section{Hiato e ditongo}

Nas palavras saúde e herói aparecem duas vogais juntas. Em ambas há um encontro vocálico (encontro de vogais e semivogais). Separando essas palavras em sílabas, teremos: sa-ú-de e he-rói. Em saúde, as vogais ficaram em sílabas diferentes porque uma não depende da outra para ser pronunciada. A essas ocorrências chamamos de hiato (que significa intervalo, lacuna). Em herói, pronunciamos os dois sons juntos, porque um som depende do outro. $\mathrm{O}$ som /i/ não pode ser separado do som /ó/. Temos uma vogal e uma semivogal que ficam juntas, em uma mesma sílaba. Essa ocorrência é chamada de ditongo.

Quadro 15. Definições de hiato e ditongo apresent. no LD2

(Fonte: Figueiredo et al., 2015, p. 281)

Nestas definições, há a referência a vogais e semivogais, mas a obra não aborda esses segmentos, para que o aluno compreenda quando, no contexto das palavras, $o$ $i$ e $u$ representam vogais e semivogais, quais são as suas características do ponto de vista articulatório e qual o seu papel na estrutura da sílaba. Didaticamente falando, a falta de abordagem desses saberes prévios compromete a plena compreensão do conteúdo referido. Além disso, o excerto apresenta uma definição sucinta e redutora do ditongo, por meio de um único exemplo de ditongo descrescente. Ao fazê-lo, furta-se de discutir questões importantes como: a variação linguística que caracteriza os ditongos, que não é, como o disse Mattoso Câmara Júnior (2011, p. 55) "[...] um traço fonêmico geral do português" e os processos fonológicos da monotongação e da ditongação, que se fazem presentes na fala de brasileiros dos mais diferentes níveis de escolaridade e classes sociais, em ocorrências como caixal ['ka $\int \mathrm{e}$ ], feira /['fere], cheirar/ [Je' 'ra], paz/['pajs], faz/ ['fajs]. Acrescente-se que, do ponto de vista didático-pedagógico, a obra, apesar da ausência de problemas relativos à precisão terminológica, apresenta conceitos incompletos e imprecisos, o que não favorece uma abordagem reflexiva acerca do fenômeno linguístico em pauta. Além disso, como não apresenta conceitos que obrigatoriamente antecedem a abordagem dos ditongos e dos hiatos - como vogal e semivogal - não propicia o diálogo entre habilidades que deveriam ter sido desenvolvidas antes.

\section{CONSIDERAÇÕES FINAIS}

Os resultados da presente pesquisa mostraram que a Fonética e a Fonologia são abordadas em apenas uma das duas obras analisadas, mas de maneira superficial e restrita. Ainda que este trabalho tenha se limitado à análise de apenas dois LD, uma investigação que ampliasse esse corpus, provavelmente, chegaria a resultados semelhantes; isso porque, como demostra Rodrigues (2020, no prelo), essas áreas são previstas pela Base Nacional Comum Curricular (Brasil, 2018) apenas para os anos iniciais do Ensino Fundamental, assim como acontece com as orientações curriculares oficiais que antecedem a BNCC, os PCN. Assim, à superação dos problemas apresentados, urge que o primeiro nível de análise 
linguística encontre o seu espaço no currículo oficial nacional, para que, então, passe a figurar nos currículos escolares, nas orientações do Programa Nacional do Livro Didático (PNLD) e, por fim, nos livros didáticos. Nesse "mundo ideal", a Fonética e a Fonologia, desde que abordadas numa perspectiva que suplantasse o formalismo e que desse conta da língua em uso, em evolução, propiciariam os subsídios teóricos necessários não apenas à superação das dificuldades de grafia dos nossos alunos da Educação Básica, como também do preconceito linguístico de que são vítimas, especialmente, as camadas menos favorecidas da sociedade.

\section{REFERENCIAS}

BRASIL. Ministério da Educação. Secretaria de Educação Básica. Programa Nacional de Livros Didáticos 2017. Guia de Livros Didáticos - Língua Portuguesa/Ensino Fundamental Anos Finais. Brasília, 2016.

BRASIL. Ministério da Educação. Base Nacional Comum Curricular. Brasília: MEC, 2018. Disponível em: http://basenacionalcomum.mec.gov.br/images/BNCC_publicacao.pdf.

CAGLiARI, L. C. Alfabetização e linguística. 11ª ed. São Paulo: Scipione, 2009.

CÂMARA JR, M. Estrutura da língua portuguesa. 43ª ed. Petrópolis: Vozes, 2008.

CÂMARA JR, M. Para o estudo da fonêmica portuguesa. Petrópolis: Vozes, 2011

COSTA, C. L.; MARCHETTI, G. Para viver juntos: português, $6^{\circ}$ ano. São Paulo: Edições SM, 2015.

FIGUEIREDO, L. \& SHIRLEY, G. et al. Singular e Plural: leitura, produção e estudos de linguagem.

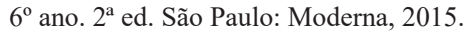

RODRIGUES. G. C. \& NASCIMENTO, G. R. P. Compreensão de professores de língua portuguesa acerca da natureza de fenômenos relacionados à fonética e à fonologia subjacentes à dificuldade de escrita de estudantes do ensino básico. In: Revista Letras e Letras, vol 32/4-julho/ dezembro/2016). Universidade Federal de Uberlândia (MG). Disponível em http://www.seer. ufu.br/index.php/letraseletras/article/view/35380/20441. (pp. 47-64).

RODRIGUES, S. G. C. \& SÁ, C. M. A Base Nacional Comum Curricular Brasileira e o Lugar da Fonética e da Fonologia no Ensino Fundamental Anos Iniciais. In: Cadernos de Estudos Linguísticos. Vol 60/3-novembro/2018. Universidade Estadual de Campinas (SP). Disponivel em https://periodicos.sbu.unicamp.br/ojs/index.php/cel/issue/view/1548.

RODRIGUES, S. G. C. e LEAL, T. F. (orgs). A BNCC em Foco: Discussões sobre Ensino de Língua Portuguesa. In: RODRIGUES, S. G. C. A Base Nacional Comum Curricular Brasileira e o Lugar da Fonética e da Fonologia no Ensino Fundamental Anos Finais. Campinas (SP): Pontes, 2020 (no prelo).

Recebido: $13 / 6 / 2019$

Aceito: $29 / 7 / 2020$

Publicado: 16/9/2020 